\title{
Functional Lumial Imaging Probe (ENDO-FLIP) for Assessment of Continence after Abdomino-Perineal Resection for Carcinoma of the Rectum Patients
}

\author{
MAMDOUH MOUNIR, M.Sc.; MOUNIR ABOUL ELA, M.D.; MOHAMED GAMIL, M.D.; \\ GAMAL AMIRA, M.D.; AHMED FARAG, M.D. and TAREK KHAIRY, M.D. \\ The Department of Surgical Oncology, National Cancer Institute, Cairo University
}

\begin{abstract}
Background: Twenty per cent of patients with carcinoma of the rectum are surgically treated with Abdomino-perineal Resection even after the recent advances in surgical techniques and the introduction of staplers. Permanent iliac Colostomy impairs the quality of life of patients after APR which raised the issue for creation of Perineal colostomy as a method of total Perineal reconstruction after APR. Which later raised the issue of objective Assessment of function as regards Continence of these patients.
\end{abstract}

Aim of the Study: This work is aiming at assessment of degree of Continence of patients suffering carcinoma of the rectum previously treated with APR followed by TPR and Perineal colostomy. An objective Assessment using the EndoFLIP was used in addition to their subjective assessment.

Material and Methods: Twenty patients with low rectal cancer previously treated with APR followed by a perineal colostomy were included. Patients were objectively evaluated using the Endo-FLIP system with correlation to their quality after life as regards continece.

Results: Considerable degree of distensibility was noted during coughing with a mean of $22.1 \mathrm{~mm}$ at the proximal segment of the colon versus 11.2 at the neo-sphincter level. Our patients were as well able to evacuate the catheter voluntarily with a mean of 3.2 seconds.

Conclusion: In conclusion, this new technique proved to be valuable in improving the QOL of patients with rectal cancer after APR. The procedure achieved 94\% patient satisfaction.

Key Words: Rectal cancer - APR - Perineal colostomy - QOL - Endo-FLIP.

\section{Introduction}

ADVANCES in surgical procedures and technology have resulted in a decrease in the proportion of patients with rectal cancer undergoing Abdomino-Perineal Resection (APR) since its introduction

Correspondence to: Dr. Mamdouh Mounir, The Department of Surgical Oncology, National Cancer Institute, Cairo University by Miles [1]. APR represents 34\% of surgical procedures for the curative treatment of carcinoma of the rectum in the National Cancer Institute (NCI), Cairo University [2]

From the patient perspective, APR resulting in a permanent stoma impairs Quality of Life (QOL) and has long-term familial, social, psychological and sexual implications in terms of stoma care. This has been addressed in a number of studies [39]. In Egypt, in addition to the aforementioned problems, there is the problem of the regular availability of the stoma appliances and its cost.

Developed more than 100 years ago, APR remains an important procedure in the treatment of rectal cancer despite advances in sphincter-sparing procedures [10]. Advances in surgical techniques and technology have resulted in a fall in the proportion of patients with rectal cancer undergoing APR to approximately $20 \%$ [11]

Perineal colostomy after APR is adopted by many dedicated centers for better QOL for patients with carcinoma of the rectum. Many procedures and techniques were described. A thorough assessment of these procedures is necessary as regards morbidity, continence level and QOL [12-15].

A proper assessment should entangle both subjective and objective parameters. Subjective assessment measures continence level as well as satisfaction and QOL. Objective assessment measures the integrity of the neo-sphincter.

\section{Objective assessment:}

\section{1- Ano-rectal physiology testing:}

It consists of a number of simple and minimally invasive test elements to measure the resting and squeeze pressure of the anal sphincter, determine 
the length of the high-pressure zone and pressure profile of the anal canal and assess the ano-rectal sensation, rectal capacity and rectal compliance [16].

The most widely used test for ano-rectal function is ano-rectal manometry. Ano-rectal manometry measures pressures of the anal sphincter muscles, sensation in the rectum, and neural reflexes that are needed for normal bowel movements. This test is mainly performed to evaluate patients with constipation or fecal incontinence [17].

\section{2- Endo-anal ultrasound:}

It provides an assessment of the thickness and structural integrity of the external and internal anal sphincter muscles and can detect the presence of scarring, loss of muscle tissue, and other local pathology. Higher frequency $(10-15 \mathrm{mHz})$ probes that provide better delineation of the sphincter complex have become available [18] .

\section{3- Magnetic Resonant Imaging (MRI):}

MRI provides visualization of the normal anatomy and pathologic conditions of the anal canal. A major contribution of anal MRI has been the recognition of external sphincter atrophy and how this may adversely affect sphincter repair. The addition of dynamic pelvic MRI or MRI that involves filling the rectum with ultrasound gel as a contact agent and having the patient evacuate this while lying inside the magnet may define the anorectal anatomy more precisely. The use of an endo-anal coil significantly enhances the resolution and allows more precise definition of sphincter muscles [19].

\section{4- Defecography:}

Defecography is useful in patients with suspected rectal prolapse or in those with poor rectal evacuation but it is otherwise of limited value. This is a radiographic test that provides morphological information regarding the rectum and anal canal and uses fluoroscopic techniques. It is used to assess several parameters such as the anorectal angle, pelvic floor descent, and length of anal canal, presence of a rectocele, rectal prolapse, or mucosal intussusception [20].

\section{5- Electromyography (EMG) of the anal sphincter:}

EMG is sometimes helpful in evaluating neurogenic or myopathic damage in patients with fecal incontinence. EMG activity of the anal sphincter can be performed using a surface electrode or a concentric needle [21].

\section{6- Pudendal nerve terminal motor latency:}

It has limited impact in the diagnosis and management of patients with fecal incontinence and is not routinely recommended [22]

\section{7- Functional Luminal Imaging Probe (FLIP):}

Endo-FLIP allows detailed evaluation of dynamic biomechanical properties along the length of the anal canal [23].

Gastrointestinal (GI) sphincters are specialized zones that serve to divide the GI tract into distinct compartments. Sphincters appear as narrow regions of the lumen of the tract, most of the time being almost closed. The various segments of the GI tract through which food and other luminal contents pass are hollow low-pressure organs that are separated by specialized sphincteric circular muscles. These sphincters are used for temporary mechanical separation of compartments for controlling the direction and flow of semisolid and liquid contents. The physiological mechanism at the anatomical site plays a fundamental role in sphincter operation, such as how sphincter muscles contract and relax [24].

\section{The Endo-FLIP System:}

The Functional Luminal Imaging Probe (FLIP) has been developed for assessment of lumen size and sphincter distensibility in the gastrointestinal tract. The FLIP determines serial Cross-Sectional Areas (CSA) and pressure during distension, thereby allowing dynamic evaluation along the length of a sphincter complex. It has been tried in studies of the gastroesophageal junction [25] and, recently, of the anal canal in healthy volunteers [26]. The FLIP procedure is easy to perform and well tolerated by all subjects [27].

The EndoFLIP System (Crospon Ltd, Galway, UK) uses a bag catheter to display in real-time lumen CSA in the GI canal with high spatial and temporal resolution. Functional Lumen Imaging Probe is based on the impedance planimetry technique where, the luminal CSA in hollow organs is determined from the electrical impedance between a pair of detection electrodes placed in a bag containing electrically conductive fluid [28]. The FLIP catheter consists of a two lumen polyethylene tube with an outer diameter of $3 \mathrm{~mm}$. It contains an array of 17 ring electrodes that measure electrical impedance for estimation of CSA at 16 points $5 \mathrm{~mm}$ apart. Hence, measurements of CSA are done for an 8-cm-long zone. A 12-cm-long bag is mounted on the probe and designed to be filled to a maximum diameter of $25 \mathrm{~mm}$. The bag pressure is determined by a solid state pressure transducer placed inside 
the bag. Cross-sectional areas measurements and pressure data are sampled at $10 \mathrm{~Hz}$ and stored in the data acquisition system. The bag is filled with specially formulated conductive solution at a rate of $40 \mathrm{~mL} / \mathrm{min}$ to a maximum infusion volume of $50 \mathrm{~mL}$ [29]. Impedance planimetry uses AC voltage measurements made between pairs of electrodes to estimate the extent of the diameter of the medium (a conductive fluid) at the mid-point between those electrodes. This can be done provided the voltage drop across the medium is generated from a constant AC current source and the conductivity of the medium is constant and known for a given temperature.

\section{- Clinical applications of endo-FLIP: \\ 1- Upper GI surgery:}

The EndoFLIP imaging catheter can be placed in the Gastroesophageal Junction (GEJ) and act as a smart bougie during laparoscopic fundoplication surgery to allow a surgeon measure how tight the GEJ has become, both after crural repair, and during and after the fundoplication wrap procedure.

Small hiatal hernias can be measured before and after repair, since the spatial separation of the crus and lower esophageal sphincter and the wrap itself can be visualized by virtue of the $8 \mathrm{~cm}$ long image field of the EndoFLIP catheter. EndoFLIP may be used to assess the GEJ at different stages during the procedures to determine whether the desired narrowing or distensibility of the Lower Esophageal Sphincter (LES) has been achieved [30].

During a Heller Myotomy for Achalasia, the EndoFLIP catheter can be placed in the GEJ. Also, when performing a myotomy trans-orally using endoscopic submucosal tunneling i.e. Per Oral Esophageal Myotomy (POEM) technique [31]

For esophageal strictures, endo-FLIP is an accurate intra-operative tool that predicts shortterm outcome following Pneumatic Dilatation (PD) for idiopathic achalasia [32] .

\section{2- Bariatric surgery:}

Intraoperative band adjustment is well tolerated. For the LapBand, intraoperative adjustments with the use of endo-FLIP system appear to improve early weight loss and this improvement appears to be maintained one year after surgery [33].

Endo-FLIP could be used to study the lower esophageal sphincter changes with laparoscopic sleeve gastrectomy [34] and to measure the stomal diameter after gastric bypass [35]

\section{3- Colorectal:}

Only few studies have evaluated anal sphincter function by means of the FLIP. Endo-FLIP system is used in measuring anal canal sphincter resistance and dispensability in healthy controls [26]

Recently it was found that the resistance of the anal canal to distension was significantly reduced in patients with idiopathic fecal incontinence [29] and in fecal incontinence secondary to systemic scleroderma [27].

Endo-FLIP system is used in measuring anal canal sphincter resistance and dispensability in healthy controls [26]. EndoFLIP has been modified to allow detailed information to be gathered about dynamic biomechanical properties along the length of the anal canal during distension [27]. Impedance planimetry can also be used intra-operatively during surgery for fecal incontinence [36]

The length of the anal canal assessed with FLIP was $3.63 \pm 0.58 \mathrm{~cm}$ in healthy volunteers [29]. There are different opening patterns observed in the Fecal Incontinence (FI) patients and the healthy subjects suggested that the resistance to the entry of stool into the anal canal was lower in the FI patients than in the healthy subjects. Fecal incontinence is associated with an abnormally high distensibility index at rest and during voluntary contraction. The EndoFLIP results were comparable to the 3D-HRM results in the (FI) patients. This distensibility technique provides an important new way of studying the anal canal and hence may have a role in testing sphincter competence in patients with disorders [26].

Intraoperative use of Endo-FLIP in colorectal surgery provides visualization of the anal canal geometry and in terms of using these measurements for input to the flow equation, which in turn may be used to predict likely surgical outcome [36]

\section{Patients and Methods}

Between February 2015 and February 2017, 117 APRs were performed in the National Cancer Institute, Cairo University. IRB and Ethical Committee approval was obtained. Perineal colostomy was created in 20 of those patients; 15 men and 5 women with mean age of 36 years.

All patients presented with low rectal adenocarcinoma, stage II to III disease, they were subject to neo-adjuvant Concomitant Chemo-Radiotherapy (CCRTH). 


\section{Inclusion criteria:}

- Immediate: Patients with operable, resectable carcinoma of the rectum undergoing AbdominoPerineal Resection.

- Delayed: Patients who underwent AbdominoPerinal Resection with "permanent" left iliac colostomy for carcinoma of the rectum, with at least 2 years disease free survival.

\section{Exclusion criteria:}

- Comorbidities contraindicating major surgery.

- Inoperable tumors either locally advanced or stage IV disease.

- Patients refusing perineal colostomy after detailed informed explanation.

\section{Interventions:}

- Pre-operative evaluation:

1- Full history and examination.

2- Full laboratory investigations.

3- Appropriate radiological investigations.

4- Colonoscopy and tissue diagnosis.

- Proper medical and anesthetic assessment.

\section{- Detailed informed consent:}

A detailed, clear, concise and informed consent is taken. The consent contains: A proposal of the idea, advantages and disadvantages, probable sequelae and complications and patients' education and instructions.

\section{- Operative technique:}

The study included 2 categories of patients; immediate reconstruction (synchronous with the APR) and delayed reconstruction (metachronous to APR).

\section{1- Immediate reconstruction:}

A- Classic conventional Abdomino-Perinal Resection.

B- Mobilization of the descending colon, splenic flexure and left half of the transverse colon after excision ligation of the upper left colic vessels preserving the marginal artery and the middle colic vessels.

\section{C-Creation of a colonic pedicled flap:}

I- Excision of the appendices epiploecae and peri-colic fat.

II- Laying open the distal $10 \mathrm{~cm}$ at its antimesenteric border.

III- Transection of this distal segment of the mobilized colon short of the marginal artery.
IV- Mucosa is curetted using a scalpel blade.

Thus a pedicled seromuscular flap is created based on the marginal vessels.

D- This pedicled seromuscular flap is wrapped around the distal colon two to four $\mathrm{cm}$ away from its lower edge. It is sutured edge to edge using interrupted vicryl 2/0.

E- Implantation of colostomy in the perineum (Perineal Colostomy):

I- The perineum is closed in 2 layers apart from the site where the stoma is pulled down.

II- The stoma is fixed in females mid-way between the tip of the coccyx posteriorly and the posterior vulval commissure anteriorly. In males, between the tip of the coccyx and the scrotum. It is sutured in place by absorbable sutures.

\section{2- Delayed reconstruction:}

A- Abdominal exploration and meticulous dissection of adhesions.

B- Creating a plane between the presacral fascia posteriorly and the posterior wall of urinary bladder in males or posterior vaginal wall in females anteriorly using sharp dissection.

C- Dissection of the left iliac colostomy from the abdominal wall and classic repair of the stoma site.

D- The same steps from b-e described in the immediate reconstruction are followed.

E- The patient is put in a lithotomy position. An elliptical incision removing the scar of previous APR.

F- Sharp meticulous dissection anterior to the precoccygeal fascia posteriorly and the posterior wall of urinary bladder in males or posterior vaginal wall in females anteriorly.

G- Pulling the distal colon through this created tract.

H- Implantation of colostomy in the perineum (Perineal Colostomy). It is sutured in place by absorbable sutures.

During the whole procedure, the vascularity and viability of both the pedicle and the stoma is meticulously monitored and assessed.

\section{-Post-operative management:}

1- Routine post-operative care.

2- Starting with the regaining of intestinal motility, daily morning colonic irrigation (enema) using $500 \mathrm{cc}$ of warm saline. 


\section{- On discharge:}

Patients were instructed about:

1- Daily colonic irrigation.

2- Regular meals at fixed times.

3- Usage of constipating measures if needed.

4- Follow-up after one month then every 3 months.

Patients were objectively evaluated regarding continence post-operatively based through manometric studies of the different pressure zones at the distal colonic segment using the Functional
Luminal Imaging Probe (FLIP) 6 months after the procedure. The Endo-FLIP System (Crospon Ltd, Galway, UK) was used. The bag was filled with specially formulated conductive solution at a rate of $40 \mathrm{~mL} / \mathrm{min}$ to a maximum infusion volume of $60 \mathrm{ml}$. Patients are assessed at rest, asked to squeeze, with Valsalva, coughing and finally asked to evacuate the catheter. The procedure was tolerable by only 14 patients. One patient died within the 1 st 6 months of treatment and 3 patients, subjectively highly satisfied with their level of continence, refused to participate in the objective assessment.
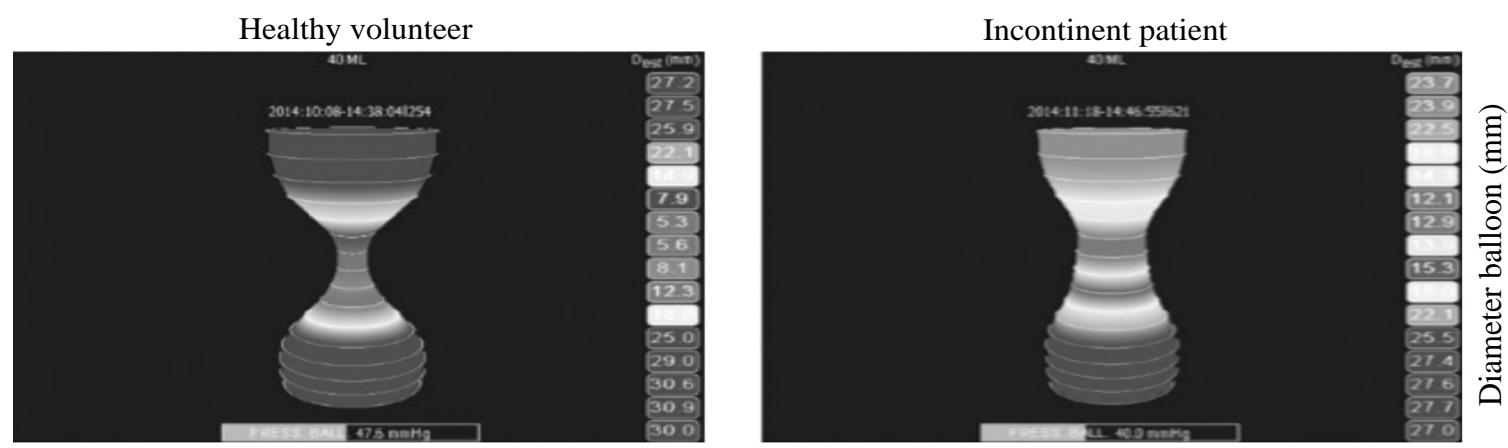

Contraction at $40 \mathrm{~mL}$
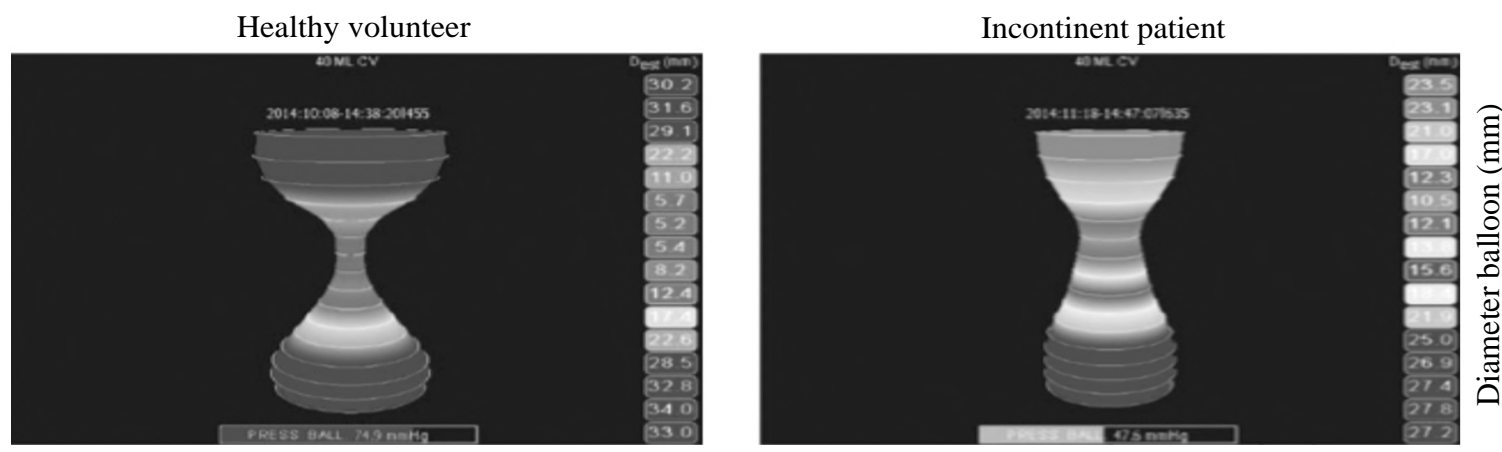

Fig. (1): Anal canal configurations by endo-FLIP in healthy volunteer and in incontinent patient at rest (upper 2 photos) and squeeze (lower 2 photos) after distension volume 40ml [26]

\section{Results}

Twenty patients underwent a perineal colostomy: 15 males $(75 \%)$ and 5 females $(25 \%)$. Fourteen patients underwent immediate reconstruction (70\%) and 6 delayed reconstruction (30\%). Two patients underwent delayed reconstruction after 2 years from their APR and 4 patients following 4 years of their initial procedure.

There was no post-operative mortality.

\section{Surgical results:}

Fifteen patients $(75 \%)$ passed a smooth postoperative course. Operative morbidity occurred in 5 patients $(25 \%)$.
Two patients (10\%) had stoma necrosis and complete sloughing of the terminal $10 \mathrm{~cm}$ of the colon as well as the flap during the first week and required reversion of the perineal colostomy into a left iliac colostomy. One developed traumatic multiple fistulous tracts with perineal suppuration due to the use of daily colonic irrigation and improved on systemic and local treatment. One patient developed mild mucosal prolapse without the need of surgical intervention. Thirty months postoperative he developed mucosal polyps, excision biopsy revealed hyperplastic inflammatory nature. One patient from the delayed reconstruction group developed urinary vesico-perineal fistula which appeared after removal of the urinary catheter on 
day 3 , treated conservatively with a silicon urinary catheter left for 2 weeks. With exclusion of the two cases that had to undergo early reversion to left iliac colostomy, 18 patients were left for evaluation of oncological and functional results.

\section{Oncological results:}

At the end of the study, 18 patients were followed-up with a mean follow-up of 24 months. Although 6 of them underwent APR for their primary disease at an earlier date; follow-up was calculated with the start of the study. All patients presented with low rectal adenocarcinoma, they were subject to neo-adjuvant CCRTH. By the end of the study, 3 patients died from the disease.

\section{Functional results.}

We used Endo-FLIP for the objective assessment of the patients. Fourteen out of the 18 patients were subject to objective assessment. One patient died within the 1 st 6 months of treatment and 3 patients, subjectively highly satisfied with their level of continence, refused to participate in the objective assessment.

In a different way of the commonly used anorectal manometric pressures at rest and during squeezing, the Endo-FLIP offers a better dynamic delineation of:

- The length of the neo-sphincter.

- The diameter of the segment during rest and on squeezing.

- The diameter of the segment itself and the proximal colonic segment of the neo-sphincter during Valsalva and coughing.

- The time and capability of evacuation.

Segment dimensions of all patients subject to Endo-FLIP are shown in (Table 1), including the incontinent patient.

Table (1): Endo-FLIP segment dimensions.

\begin{tabular}{lll}
\hline Segment dimensions & Mean & Range \\
\hline Segment length $(\mathrm{cm})$ & N/A* & $4.5-\mathrm{N} / \mathrm{A}$ \\
At rest $(\mathrm{mm})$ & 14.7 & $12-27$ \\
Squeeze $(\mathrm{mm})$ & 10.8 & $7-25$ \\
Valsalva $(\mathrm{mm})$ & 12.8 & $9-26$ \\
Coughing $(\mathrm{mm}):$ & & \\
$\quad$ Sphincter & 12.2 & $8-25$ \\
$\quad$ Proximal segment & 22.3 & $19-25$ \\
Evacuation (sec.) & N/A & $3-\mathrm{N} / \mathrm{A}$ \\
\hline
\end{tabular}

*: Could not be assessed.
Segment dimensions in the incontinent patient revealed a structure less tube, without any changes during the whole phase of the procedure Fig. (1) rendering its assessment useless and influencing the results of the other patients.

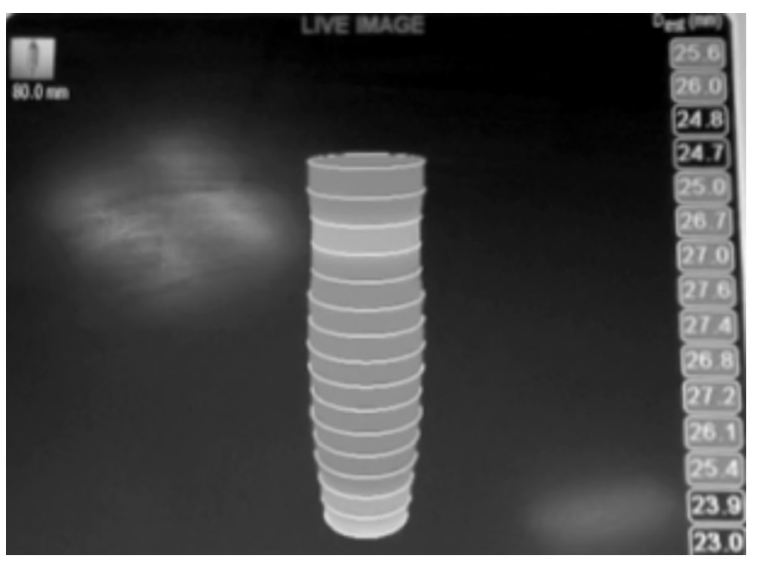

(A) At rest

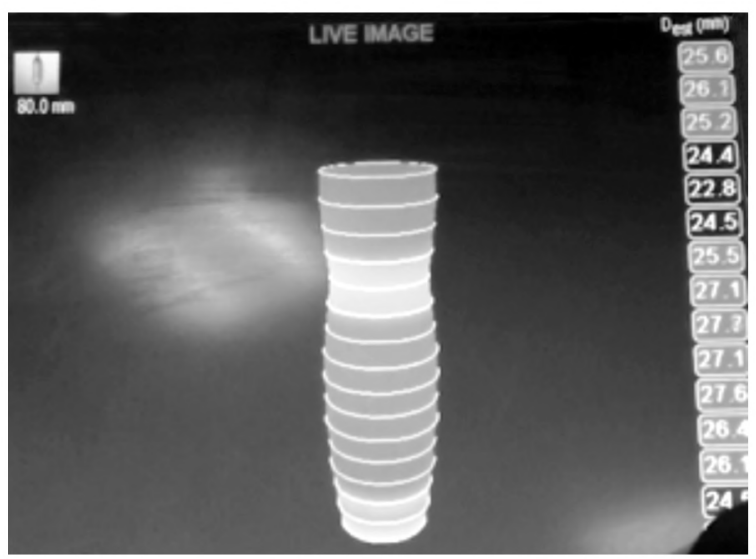

(B) On squeezing

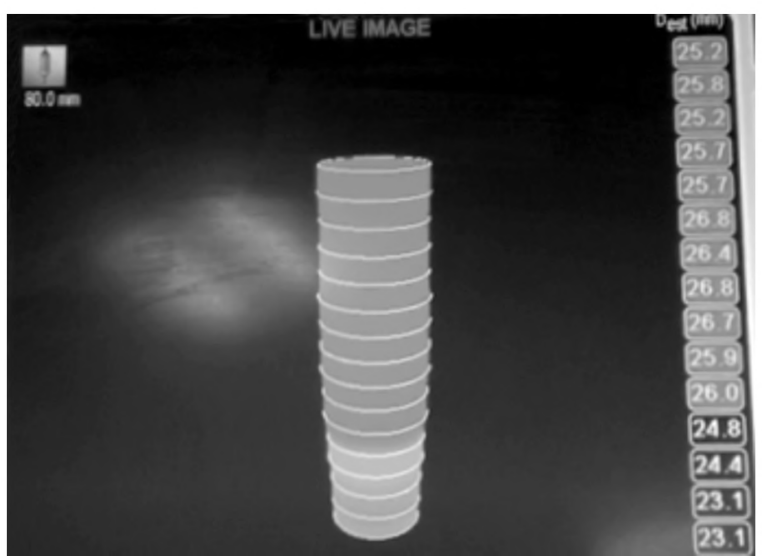

(C) On cough

Fig. (2): Endo-FLIP of the incontinent patient.

Thus his results as a confounder were excluded. The segment dimensions of the remaining 13 patients are summarized in (Table 2). 


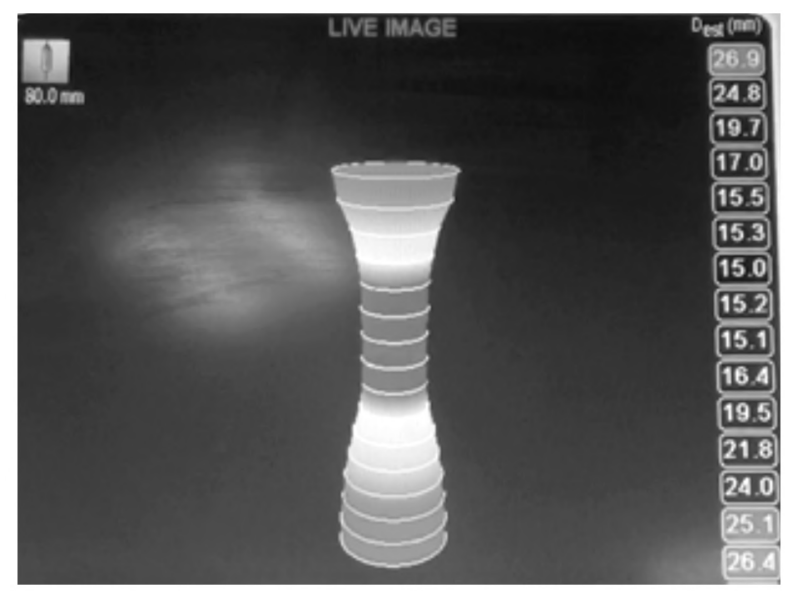

(A) At rest

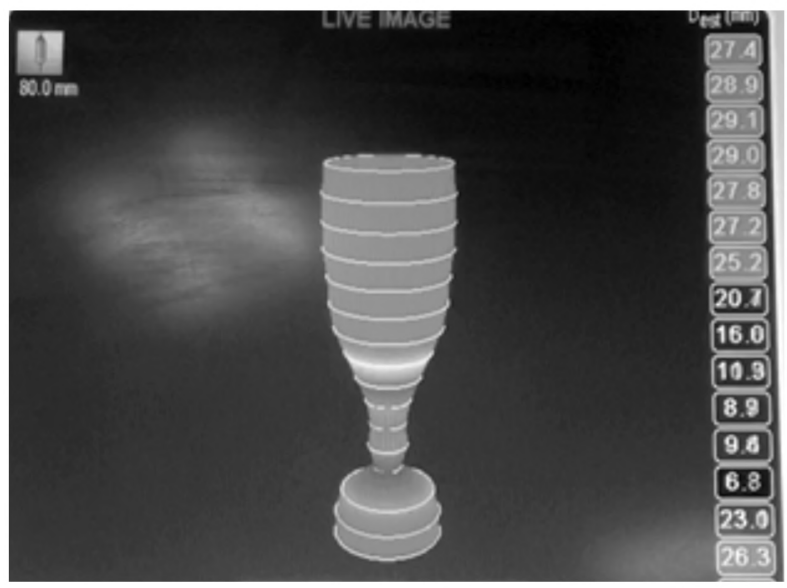

(B) On squeezing

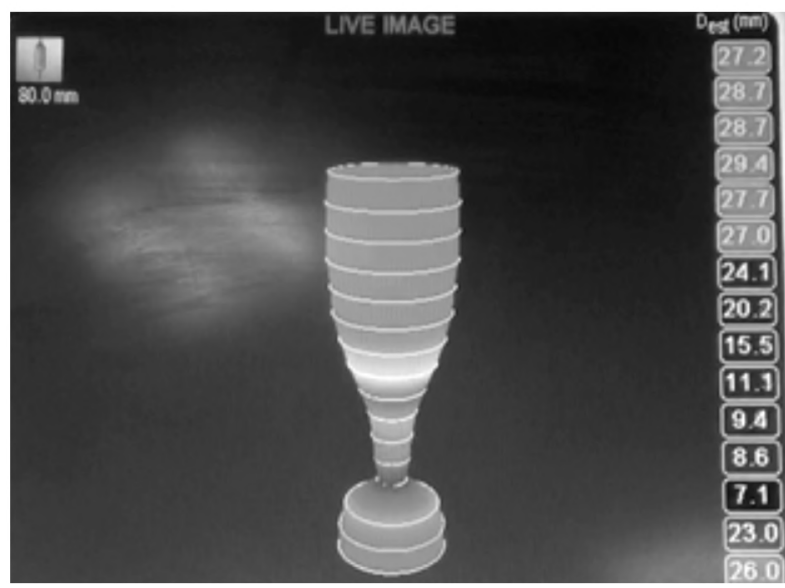

(C) On cough

Fig. (3): Illustrates the Endo-FLIP results of one patient continent to both stool and gas.

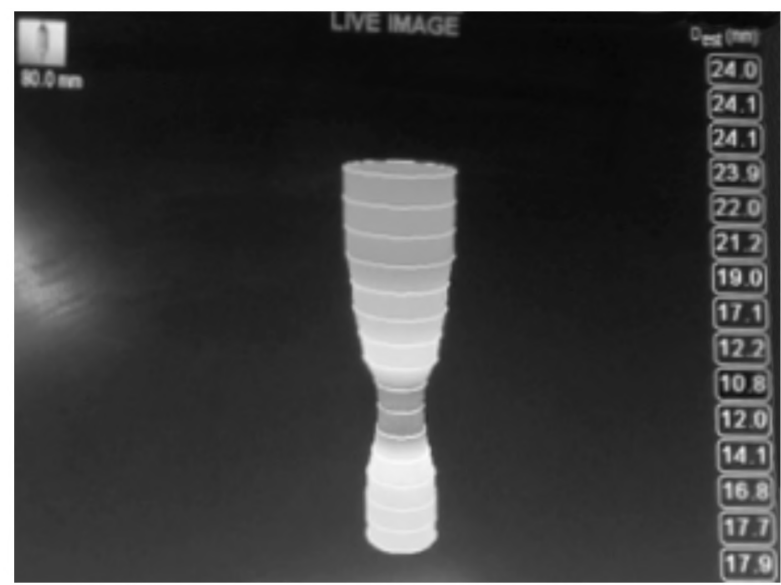

(A) At rest

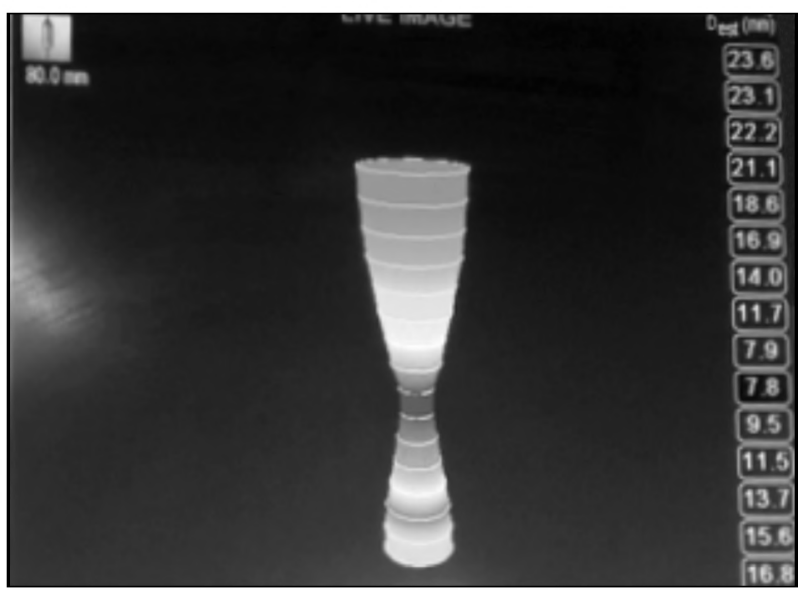

(B) On squeezing

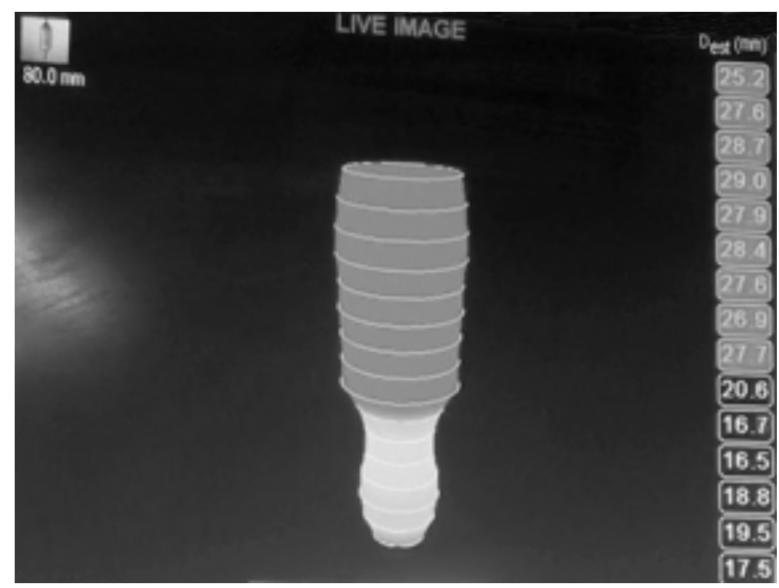

(C) On cough

Fig. (4): Illustrates the endo-FLIP results of one patient continent to stool but incontinent to gas. 


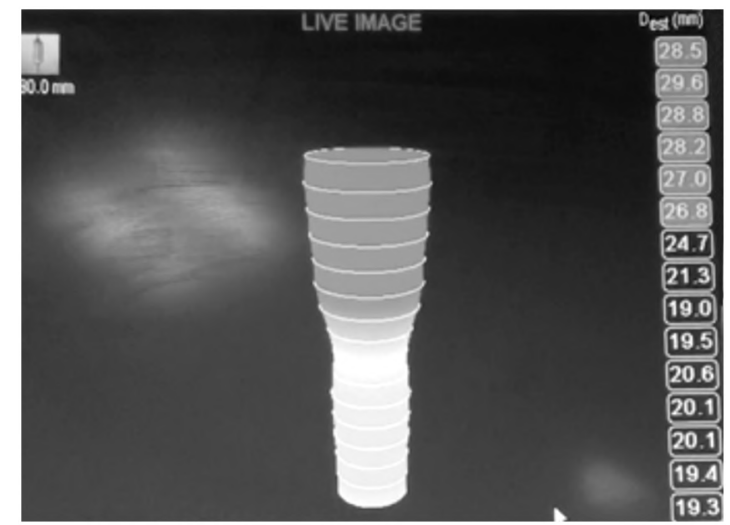

(A) At rest

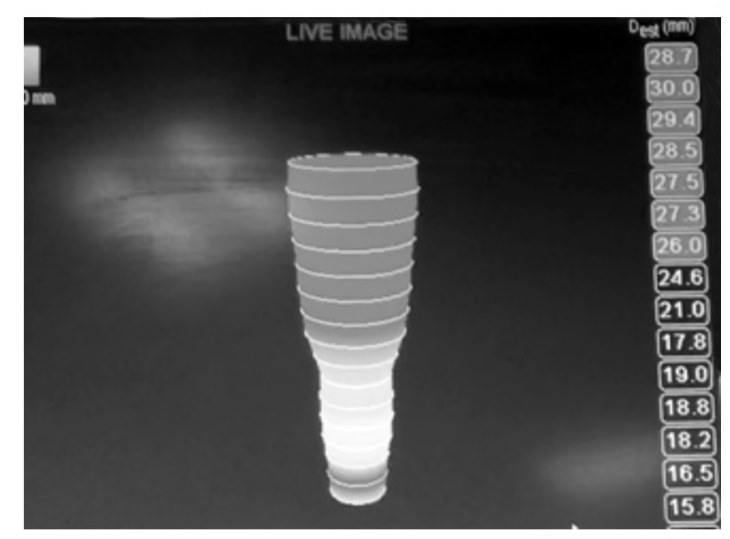

(B) On squeezing

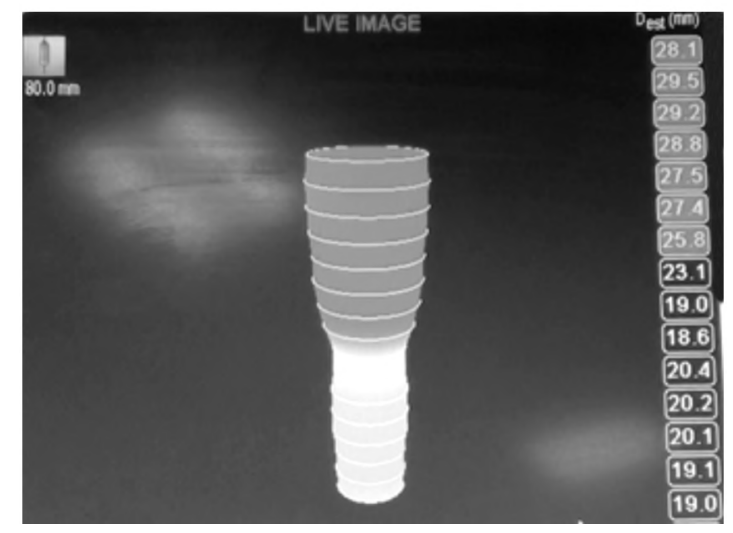

(C) On cough

Fig. (5): Illustrates the endo-flip results of one patient with minor soiling.

Table (2): Endo-FLIP segment dimensions after excluding the confounder.

\begin{tabular}{lll}
\hline Segment dimensions & Mean & Range \\
\hline Segment length $(\mathrm{cm})$ & 5.3 & $4.5-7$ \\
At rest $(\mathrm{mm})$ & 13.8 & $12-16$ \\
Squeeze $(\mathrm{mm})$ & 9.8 & $7-12$ \\
Valsalva $(\mathrm{mm})$ & 12 & $9-14$ \\
Coughing $(\mathrm{mm}):$ & & \\
$\quad$ Sphincter & 11.2 & $8-13$ \\
$\quad$ Proximal segment & 22.1 & $19-24$ \\
Evacuation (sec.) & 3.2 & $3-5$ \\
\hline
\end{tabular}

\section{Discussion}

Many procedures and techniques for perineal colostomy have been devised, abounded, revisited, renovated, modified, innovated and so on. The multiplicity of these procedures certifies that no one of them is ideal and each has its merits.

This study is a prospective observational clinical trial aiming at improving the QOL of patients after APR for carcinoma of the rectum.

This study presents an unprecedented innovative technique in a trial to partially simulate the internal smooth muscle sphincter of the anorectal complex. The technique entangles the creation of a pedicled (CSMC) maintaining its vascular and nervous supply through the integrity of the marginal artery of Drummonds.

As any CSMC technique, ours is relatively simple compared to dynamic gracilopalsty, gluteoplasty and artificial bowel sphincters. CSMC is done through the same incision, within the vicinity of the field and without neither synthetic materials nor skeletal muscle transposition.

In accordance with different series using different techniques, our procedure proved to be safe where there is neither operative nor post-operative mortality.

The results of this study proved to be comparable to the published data regarding both surgical and functional results.

In our study we reported $25 \%$ complication rate compared to $22-76 \%$ in similar series using CSMC. Apart from the 2 patients (10\%) with stoma necrosis that needed reversion, the remaining 3 (15\%) were conservatively treated.

It is worth noting that in our study, none of the patients developed stenosis of the neo-sphincter. This could be explained by the aforementioned advantages of the vascularized flap.

Continence was achieved in 13 patients, 2 of them for both gas and stools. Minimal soiling affected 4 patients. Only 1 out of 18 patients suffered incontinence.

Functional results were objectively assessed using the Endo-Flip. Although the most widely used test for pressure measurements is the anorectal manometry [17], the Endo-FLIP allowed more detailed evaluation of dynamic biomechanical properties along the length of a sphincter in healthy volunteers and patients with incontinence [23] 
It is to be mentioned that pressure parameters measured after all types of reconstruction (CSMS, DGP, gluteoplasty and ABS) were inferior to those recorded in healthy volunteers $[37,38]$. These measures were even equivalent to those in incontinent patients [39]. The impedance planimetry of our patients was similar to other different techniques. Even when compared to healthy volunteers and patients with incontinence [26], it remains towards incontinent patients. At the end, although objective functional levels are below normal, high level of satisfaction is achieved, especially in delayed reconstruction patients.

Despite this limited objective continence levels, QOL after perineal colostomy is generally accepted and even similar to SSR with colo-anal anastomosis [40], and by far higher when compared to iliac colostomy $[41,42]$.

Anorectal reconstruction techniques are merely addressing sphincter action in the context of continence, without having an optimal replacement for anorectal sensation, evacuation and reservoir capacity.

However, using the Endo-FLIP in our study with its added dynamic value, considerable degree of distensibility was noted during coughing with a mean of $22.1 \mathrm{~mm}$ at the proximal segment of the colon versus 11.2 at the neo-sphincter level. Our patients were as well able to evacuate the catheter voluntarily with a mean of 3.2 seconds.

Difficult evacuation was a common problem observed in almost all the published data, regardless of the technique. The majority of patients ended with the need of lifelong irrigation and/or laxative use to improve evacuation. This was not the case in our study where only 2 patients continued to use colonic irrigation. Four patients did not use colonic irrigation at all, the rest $(\mathrm{n}=11)$ were weaned during a period of 1 to 3 months and none used laxative treatment.

Regarding sensation, 9 of our patients, over time and adaptation to gastro-colic reflex, developed a different kind of sensation in the form of pelvic gurgling prior to the definitive urge of defecation.

Most of the published data are case series which do not carry the same level of evidence compared to randomized controlled trials. Although these procedures are practiced by expert surgical teams in highly specialized centers, each is enthusiastic towards the technique he masters.

\section{References}

1- MILES W.E.: A method of performing abdominoperineal excision for carcinoma of the rectum and of the terminal portion of the pelvic colon. Lancet, 2: 1812-3, 1908.

2- ELATTAR I.: Annual cancer conference of the Egyptian cancer society. Abstract book, 2015.

3- OLBRISCH M.E.: Development and validation of the ostomy adjustment scale. Rehabil. Psychol., 28: 3-12, 1983.

4- NUGENT K.P., DANIELS P., STEWART B., et al.: Quality of life in stoma patients. Dis. Colon. Rectum., 42: 156974, 1999.

5- SILVA M.A., RATNAYAKE G. and DEEN K.I.: Quality of life of stoma patients: Temporary ileostomy versus colostomy. World J. Surg., 27: 421-4, 2003.

6- SCARPA M., BAROLLO M., POLESE L., et al.: Quality of life in patients with an ileostomy. Minerva Chir., 59: 23-9, 2004.

7- ORKIN B.A. and CATALDO P.A.: Intestinal Stomas. The ASCRS Textbook of Colon and Rectal Surgery, 622-42, 2007.

8- ROBERT S.K., LISA J.H., MARCIA G., et al.: HealthRelated Quality of Life among Long-Term Rectal Cancer Survivors with an Ostomy: Manifestations by Sex. Journal of Clinical Oncology, 27: 4664-70, 2009.

9- KONANZ J., HERRLE F., WEISS C., et al.: Quality of life of patients after low anterior, intersphincteric, and abdominoperineal resection for rectal cancer-a matchedpair analysis. Int. J. Colorectal. Dis., 28: 679-88, 2013.

10-BRIAN W.P. and CHRISTOPHER J.C.: Abdominoperineal Resection: How Is It Done and What Are the Results? Clin. Colon Rectal. Surg., 20: 213-20, 2007.

11- TILNEY H.S., HERIOT A.G., PURKAYASTHA S., et al.: A national perspective on the decline of abdominoperineal resection for rectal cancer. Ann. Surg., 247: 77-84, 2008.

12- SCHMIDT: The continent colostomy. World J. Surg., 6: 805-9, 1982.

13- LASSER P., et al.: Pseudo-continent perineal colostomy after amputation of the rectum for cancer. Gastroenterol. Clin. Boil., 17: 181-6, 1993.

14- FEDEROV V.D., ODARYUK T.S., SHELYGIN Y.A., et al.: Method of creation of a smooth-muscle cuff at the site of the perineal colostomy after extirpation of the rectum. Dis. Colon. Rectum., 32: 562-6, 1989.

15- LASSER P., DUBE P., ELIAS D., et al.: Pseudocontinent perineal colostomy following abdominoperineal resection: Technique and findings in 49 patients. Eur. J. Surg. Oncol., 27: 49-53, 2001.

16- CHOE J.H., CHOO M.S. and LEE K.S.: The impact of tension-free vaginal tape on overactive bladder symptoms in women with stress urinary incontinence: Significance of detrusor overactivity. J. Urol., 179: 214-9, 2008.

17- BANSAL N., SACHDEVA M., JAIN P., RANJAN P. and ARORA A.: Anorectal manometry: Current techniques and indications. JIMSA, 26: 169-70, 2013. 
18- WASSERBERG N., MAZAHERI A., PETRONE P., TULCHINSKY H. and KAUFMAN H.S: Threedimensional endoanal ultrasonography of external anal sphincter defects in patients with faecal incontinence: Correlation with symptoms and manometry. Colorectal Dis., 13: 449-53, 2011.

19- WILLIAMS A.B., MALOUF A.J., BARTRAM C.I., HALLIGAN S., KAMM M.A. and KMIOT W.A.: Assessment of external anal sphincter morphology in idiopathic fecal incontinence with endocoil magnetic resonance imaging. Dig. Dis. Sci., 46: 1466-71, 2001.

20- LOCKHART M.E., FIELDING J.R., RICHTER H.E., et al.: Reproducibility of dynamic MR imaging pelvic measurements: A multi-institutional study. Radiology, 249: 534-7, 2008.

21- IAN M., MADHULIKA G.V., ANDREAS M.K, SCOTT R.S. and JANICE F.R.: The American Society of Colon and Rectal Surgeons' Clinical Practice Guideline for the Treatment of Fecal Incontinence. Dis. Colon. Rectum., 58: 623-36, 2015.

22- DUDDING T.C., PARES D., VAIZEY C.J. and KAMM M.A.: Sacral nerve stimulation for the treatment of faecal incontinence related to dysfunction of the internal anal sphincter. Int. J. Colorec. Dis., 25: 625-30, 2010.

23- LUFT F., FYNNE L., GREGERSEN H., et al.: Functional luminal imaging probe: A new technique for dynamic evaluation of mechanical properties of the anal canal. Tech. Coloproctol., 16: 451-7, 2012.

24- CHRISTIAN L., HANS G., DONGHUA L., LOTTE F., JENS B.F., et al.: Functional lumen imaging of the gastrointestinal tract. J. Gastroenterol., 50: 1005-16, 2015.

25- MCMAHON B.P., FROKJAR J.B. and KUNWALD P.: The functional lumen imaging probe (FLIP) for evaluation of the esophagogastric junction. Am. J. Physiol. Gastrointest. Liver Physiol., 292: 377-84, 2007.

26- ALQUDAH M.M., GREGERSEN H., DREWESA.M. and MCMAHON B.P.: Evaluation of anal sphincter resistance and distensibility in healthy controls using EndoFLIP. Neurogastroenterol. Motil., 24: 591-9, 2012.

27- FYNNE L., LUFT F., GREGERSEN H., et al.: Distensibility of the anal canal in patients with systemic sclerosis: A study with the functional lumen imaging probe. Colorectal Dis., 15: 40-7, 2012.

28- GREGERSEN H.: Biomechanical methods and analysis. Biomechanics of the Gastrointestinal Tract: New Perspectives in Motility Research and Diagnostic. Heidelberg: Springer, 73-135, 2007.

29- SORENSEN G., LIAO D., LUNDBY L., et al.: Distensibility of the anal canal in patients with idiopathic fecal incontinence: A study with the functional lumen imaging probe. Neurogastroenterol. Motil., 26: 255-63, 2014.

30- MARJOUX S., ROMAN S., ROBERT M., et al.: Impaired postoperative EGJ relaxation as a determinant of post laparoscopic fundoplication dysphagia: A study with highresolution manometry before and after surgery. Surg. Endosc., 6: 3642-9, 2012.

31- PERRETTA S., DALLEMAGNE B., MCMAHON B., D'AGOSTINO J. and MARESCAUX J.: Improving functional esophageal surgery with a "smart" bougie: Endoflip. Surgical Endoscopy, 9: 3109-3109, 2011.

32- DUSTIN A.C., SREEDEVI A., MICHELLE B., ZOE L., PETER K. and JOHN P.: Hydraulic Dilation for Achalasia: A Series Utilizing a 30-mm Functional Lumen Imaging Probe Dilator, the EsoFLIP. Gastrointestinal Endoscopy, Issue 5, Supplement, May 2016.

33- SNOW R.G. and O'DEA J.: Does intraoperative gastric band adjustment to a targeted stoma size improve weight loss? One-year results of a feasibility trial. Bariatric Times, (9): 10-2, 2012.

34- REYNOLDS J.L., ZEHETNER J., SHIRAGA S., LIPHAM J.C. and KATKHOUDA N.: Intraoperative assessment of the effects of laparoscopic sleeve gastrectomy on the distensibility of the lower esophageal sphincter using impedance planimetry. Surgical Endoscopy, 30: 4904-9, 2016.

35- HENEGHAN H.M., YIMCHAROEN P., BRETHAUER S.A., KROH M. and CHAND B.: Influence of pouch and stoma size on weight loss after gastric bypass. Surgery for Obesity and Related Diseases, 8: 408-15, 2012.

36- FARAG A. and O'DEA J.: Intra-operative use of impedance planimetry during surgery for Fecal Incontinence. Gastroenterology, 148: 827-827, 2015.

37- GUNDLING F., SEIDL H., SCHMIDT T., et al.: Influence of gender and age on anorectal function: Normal values from anorectal manometry in a large Caucasian population. Digestion, 81: 207-13, 2010.

38- LI Y., YANG X., XU C., et al.: Normal values and pressure morphology for three-dimensional high resolution anorectal manometry of asymptomatic adults: A study in 110 subjects. Int. J. Colorec. Dis., 28: 1161-8, 2013.

39- OTTO S., GRONE J., BUHR H.J., et al.: Repeatability of anorectal manometry in healthy volunteers and patients. J. Surg. Res., 185: 85-92, 2013.

40- POCARD M., ELIAS D., LASSER P., et al.: Functional results and quality of life for patients with very low rectal cancer undergoing coloanal anastomosis or perineal colostomy with colonic muscular graft. Eur. J. Surg. Oncol., 33: 459-62, 2007.

41- ROMANO G., La TORRE F., CUTINI G., et al.: Total anorectal reconstruction with the artificial bowel sphincter: Report of eight cases. A quality-of-life assessment. Dis. Colon. Rectum., 46: 730-4, 2003.

42- SATO T., KONISHI F., ENDOH N., et al.: Long-term outcomes of a neo-anus with a pudendal nerve anastomosis contemporaneously reconstructed with an abdominoperineal excision of the rectum. Surgery, 137: 8-15, 2005. 


\section{التقييم الموضوعى لآسلوب جراحى مبتكر لوضع فتحة الشرج الصناعية الصنية

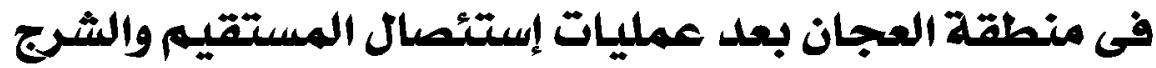

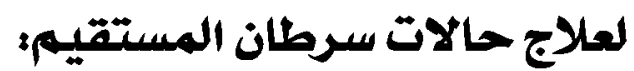 من آجل آسلوب حياة سآ سآ آفضل}

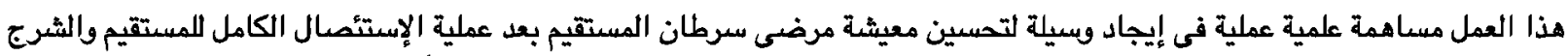

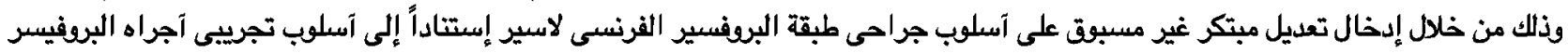

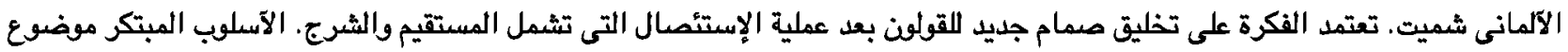

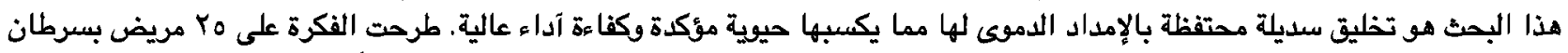

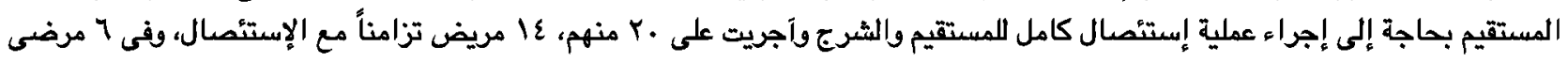

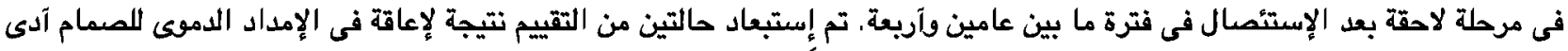

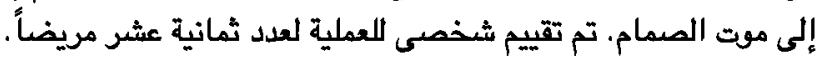
آسفرت النتائج عن: • ثلاثة عشر هريضاً يتحكمون فى عملية التبرز، إثنان منهم يتحكمان آيضاً فى إخراج الغازات. • • آربعة مرضى عانوا من بلل مخاطى بسيط آمكنهم التكيف والتفاعل معه. • عشرة مرضى ثبت تحكمه فى عملية إخراج البراز دون الإستعانة بالحقن الشرجية. التقييم الموضوعى آجرى عن طريق إستخدام جهاز (مسبر تصوير وظيفة التجويف) وآسفرت النتائج عن: • • متوسط طول الصمام r. مسم.

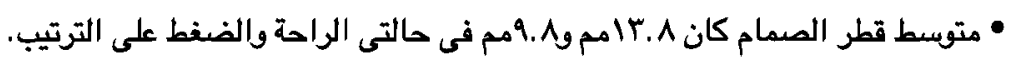

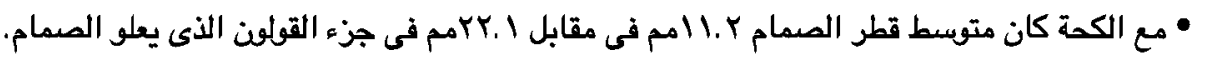

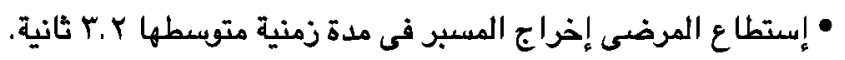
هذا النسق يشبه نتائج الشخص الطبيعى ولكن بمعدلات آقل.

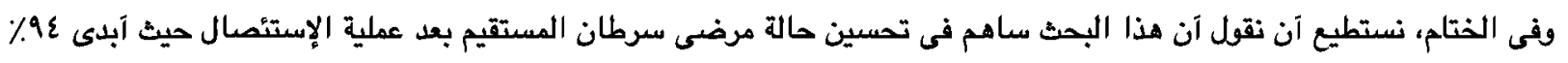

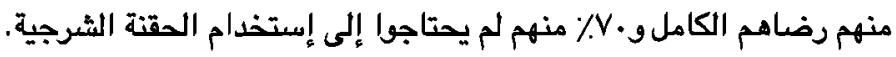
نوصى بعرض الفكرة على مرضى سرطان المستقيم الذين يحتاجِن إلى الإستئصال الكامل المستقيم والشرج حيث ثبت آنه آمن ويمكن 